\title{
The impact of supplementary short rest breaks on task performance - A meta-analysis ${ }^{1}$
}

\author{
Johannes WENDSCHE², Andrea LOHMANN-HAISLAH³ , Jürgen WEGGE ${ }^{4}$
}

\begin{abstract}
Within-shift rest breaks are important to prevent an accumulation of impairing short-term effects of strain over working time. In this meta-analysis ( $k=11$, $N=705)$, we investigated how supplementary, frequent short rest breaks affect task performance and strain. We found positive effects on quality $(g=0.23)$ and quantity $(g=0.12)$ measures of task performance. The mean reduction of working time due to rest breaks was 9.3\%. Performance improvements occurred not at costs of higher strain. Thus, our study shows that both employees' performance and well-being benefits from scheduled within-shift breaks. We found no further effects of potentially moderating variables. Future research should examine the boundary conditions and underlying mechanisms of these effects.
\end{abstract}

Keywords: meta-analysis, performance, recovery, rest breaks, strain.

\footnotetext{
${ }^{1}$ Author Note: The authors have no actual or potential financial and other conflicts of interest related to the submitted manuscript. This study was part of the project "Mental health in the working world - current state of scientific evidence" (F2353) granted by the German Federal Institute of Occupational Health and Safety and the first authors dissertation thesis. We would like to thank Beate Beermann, Martina Morschhäuser, Martin Schütte, Anne Marit Wöhrmann, and two anonymous reviewers for their helpful comments on earlier drafts of this paper.

Correspondence concerning this article should be addressed to Johannes Wendsche, Federal Institute for Occupational Safety and Health (Germany). Date of submission: 30.05.2016

${ }^{2}$ Dipl.-Psych. Johannes Wendsche is a research fellow at the Federal Institute for Occupational Safety and Health (Fabricestr. 8, D-01099 Dresden), Germany. He received a Diploma (2007) in psychology from TU Dresden (Germany). His research focuses on recovery from work stress, job analysis, job design, and turnover behavior.

E-mail: wendsche.johannes@baua.bund.de.

${ }^{3}$ Dipl.-Psych. Andrea Lohmann-Haislah is a research fellow at the Federal Institute for Occupational Safety and Health (Nöldnerstr. 40-42, D-10317 Berlin), Germany. She received a Diploma (1997) in psychology from Freie Universität Berlin. Her research focuses on recovery from work stress, job analysis, and job design. She is the author of the German Stressreport 2012. E-mail: lohmann-haislah.andrea@baua.bund.de.

${ }^{4}$ Prof. Dr. Jürgen Wegge is currently a full professor of work and organizational psychology at the Technical University of Dresden (Department of Psychology, TU Dresden. D-01062 Dresden), Germany. He earned his Ph.D. (1994) in industrialorganizational psychology from the Technical University of Dortmund. His research interests are in the field of work motivation, leadership, demographic change, and occupational health. E-mail: juergen.wegge@tu-dresden.de.
} 


\section{Introduction}

Rest breaks are within-shift interruptions between periods of planned work aiming to provide time for recovery from impairing consequences of mental and physical strain and to prevent their development and accumulation over the working day (Graf et al. 1970). This is a central ergonomic standard in the design of work systems (DIN EN ISO 6385 2004; DIN EN ISO 10075-2 2000). During a rest break working is formally not required or expected (Graf et al. 1970; Trougakos/Hideg 2009).

After one century of research, there is wide evidence that rest breaks can improve employees' well-being, health, and work safety (Nachreiner et al. 2010; Tucker 2003). Therefore, in most countries national legislation requires to provide employees at least one longer mandatory and mainly unpaid rest break after a certain amount of working hours (McCann 2005). Several studies found that employees might benefit from more frequently scheduled, short rest breaks over the working day (Tucker 2003). Notably, it is argued that positive effects of such rest break schedules on task performance can even compensate a loss of productive working time due to more time for recovery (Graf et al. 1970). Therefore, these rest breaks could as well be scheduled as paid working time. However, a quantitative review concerning this assumption is still missing. To fill this gap, we conducted a meta-analysis of studies investigating the impact of such rest breaks on task performance and strain.

\section{Theoretical Background}

Intuitively, after a period of demanding work, especially if endurance performance limits are exceeded, rest is necessary to recover from impairing short-term consequences of strain such as physical and mental fatigue or fatigue-related states such as monotony or mental satiation (DIN EN ISO 10075-1 2000; Scholz 1970). Recovery is a process wherein "the psychophysiological systems that were activated during work will return to and stabilize at a baseline level, that is, a level that appears in a situation in which no special demands are made on the individual." (Geurts/Sonnentag 2006: 483) or in more general terms "the continuous process of harmonizing the 'actual state' with the 'required state"' (Zijlstra et al. 2014: 250).

Managers and supervisors should think carefully about how they organize sufficient recovery periods for their employees as enhanced strain levels have been meta-analytically associated with lower motivation, lower job satisfaction, lower work performance, lower work safety, and higher withdrawal behavior and turnover rates (LePine et al. 2005; Nahrgang et al. 2011; Podsakoff et al. 2007).

Recovery periods can be organized within work shifts (internal recovery) such as rest breaks or between work shifts (external recovery) such as the daily rest after work at evenings, the weekend, or a vacation (Geurts/Sonnentag 2006). In most countries over the world, national legislation regulates at least some standards for internal and external recovery periods (Linder/Nygaard 1998; McCann 2005).

Rest break organization in practice represents a complex system where several variables and their interplay have to be considered (Wegge et al. 2014). For instance, this concerns the 
distribution of time for work and recovery within a shift (i.e., the length, the frequency, and the timing of breaks), the predictability of rest breaks, employees' control over the rest break schedule, the formalization of rest breaks, and the payment of rest break time (Müller-Seitz 1996; Tucker 2003; Wegge et al. 2014).

First experimental investigations to identify organizational principles of so called "worthwhile breaks" (Kraepelin 1902) for physical (Manzer 1927) and mental work (Amberg 1895; Rivers/Kraepelin 1896) date back to end of the 19th century. This research aimed to find rest break schedules at which a potential quantitative loss of task performance due to paid rest break time is fully compensated by beneficial effects of rest breaks (Graf 1922, 1927; Graf et al. 1970; Rohmert 1973a,b).

Findings of this as well as subsequent research (Bokranz 1985; DIN EN ISO 10075-2 2000; Konz 1998; Rohmert 1973a,b; Tucker 2003) suggested the following characteristics of worthwhile rest breaks: (a) they are included in the agreed (paid) working time, (b) they are short in duration, i.e., shorter than 15 minutes from a legislative perspective (Schmidtke 1993) or, from a more functional perspective, between three and ten minutes (Richter/Hacker 2014), and (c) they are scheduled frequently, i.e., several times during the working day. Moreover such rest breaks should be (d) scheduled in advance by the management meaning that they are on the one hand authorized and, on the other hand, timing (i.e., start, duration, and end) of breaks is pre-determined and predictable.

In the following, we will discuss some theoretical arguments and findings that underline these principles of rest break organization. Moreover, we will explain how it is possible to improve employees' task performance by changing the balance of work and recovery.

\section{Factors affecting task performance}

Work performance is a multi-dimensional construct relating to task and contextual performance. According to Campbell et al. (1993) psychophysical (i.e., declarative knowledge, procedural knowledge, and skills) and motivational factors (i.e., effort investment and persistence) determine work performance. Results of a meta-analysis (LePine et al. 2005) support this assumption and found that impairing mental strain symptoms $\left(\mathrm{r}_{\mathrm{c}}=-.21\right)$ and motivation $\left(r_{c}=.44\right)$ both predicted work performance, even when adjusting single effects for each other. In our review, we only focus on rest break mechanisms affecting task performance, thus, on in-role behavior to reach goals that are formally expected from the employee (Sonnentag et al. 2008). Building upon Graf's $(1922$, 1927) theory of worthwhile rest breaks, we propose that rest breaks can have both beneficial and inhibiting effects on task performance (Wendsche/Wegge 2014). A rest break is worthwhile under conditions at which a loss of potentially productive working time due to time for resting is fully compensated by positive direct and indirect effects of rest breaks on task performance. In such cases beneficial effects of rest breaks on task performance outweigh their impairing effects.

\section{Beneficial effects of supplementary short rest breaks}

Rest breaks can improve task performance through beneficial strain-related, cognitive, affective, and motivational mechanisms. 
Strain-related mechanisms. Impairing consequences of strain are determined by the level of work demands (DIN EN ISO 10075-1 2000; Meijman/Mulder 1998) and the temporal characteristics of the exposure to these demands (Schmidtke 1993). Such effects depend on the configuration of the quality, the quantity, the duration, and temporal dynamics of work demands (Bakker/Demerouti 2007; Schmidtke 1993; Sonnentag/Frese 2012). Supplementary, frequent short rest breaks prevent the development and accumulation of impairing strain outcomes in several ways. They reduce total working time and, thus, the duration of work demands as they are included in the agreed (paid) working time. This should decrease physical and mental strain outcomes. For instance, several meta-analyses found that shorter total working hours relate to lower physical and mental strain outcomes (Ng/Feldman 2008; Nixon et al. 2011; Sparks et al. 1997). This is in line with assumptions from the Effort-Recovery Model (Meijman/Mulder 1998) suggesting that impairing strain outcomes increase with time on duty as mental and physical resources that are needed for task execution are drained. Importantly, increases in impairing strain outcomes accelerate with time on task as individuals might have to invest compensatory effort to reach their goals which further increases resource depletion (Meijman/Mulder 1998; Rohmert 1973a,b). Accordingly, rest breaks should be scheduled early and frequently. Moreover, recovery from strain outcomes follows regressive curves (Lehmann 1962). Thus, relative recovery is higher for shorter than longer rest breaks. Moreover, with increasing work demands time for total recovery from impairing strain outcomes increases (Rohmert 1973a,b). This supports in addition the idea of preferable early and frequently scheduled rest breaks.

Cognitive mechanisms. It has been found that rest breaks have positive cognitive effects. More specifically, results from two meta-analyses suggest that short rest breaks improve critical performance outcomes as learning, skill acquisition (Donovan/Radosevich 1999), and problem-solving (Sio/Ormerod 2009) which all relate to task performance.

Affective mechanisms. Graf $(1922,1927)$ suggested that scheduled rest breaks might have a positive 'emotional value' meaning that individuals positively anticipate the pre-planned relaxing break incorporating a relief from work demands. Research on the Broaden-and-BuiltTheory of Positive Emotions (Fredrickson 2013) suggests that positive emotions improve well-being, attention, recovery from strain, and task performance. Thus, frequently scheduled rest breaks will accumulate this increase in positive affect which, in turn, will improve task performance.

Motivational mechanisms. Early research showed that (sub-)task allocation over total working time is important for performance. According to Motivational Intensity Theory (Brehm/Self 1989) individuals' effort investment for goal attainment follows a conservation principle. Thus, they do not mobilize more energy than necessary to reach the anticipated goals. Accordingly, some studies found an inverse relationship between expected time on task and task performance (Barmack 1939; Ross/Bricker 1951). More frequent scheduled rest breaks will divide the total working time into shorter bouts of work. This increases individuals' relative effort investment and, in turn, their task performance. Studies on the 'curve of work' found that individuals increase the speed of work at the end of a work period (Kraepelin 1902). Thus, task performance will increase under frequently scheduled rest breaks where these end-spurt effects could accumulate. Another motivational mechanism concerns the ac- 
tual task-related use of working time. Several studies showed that frequently scheduled short rest breaks reduce time for unofficial breaks (Bhatia/Murell 1969; Graf et al. 1970; Lehmann 1958; McGehee/Owen 1940). Accordingly, such rest breaks improve the task-related use of total working time, increasing task performance.

\section{Inhibiting effects of supplementary short rest breaks}

Prior research also found that at least three inhibiting mechanisms can decrease task performance under fixed schedules with supplementary short rest breaks: A potential increase in work intensity, demands from interruptions of the work flow, and a loss of practice and motivation.

Increasing work intensity. Supplementary rest breaks reduce the total potentially productive working time. Therefore, task goals have to be accomplished in shorter time and, in turn, work intensity and time pressure might increase. Such indicators of workload have been linked to higher mental and physical strain (Bowling et al. 2015). This might suggest a decrease in task performance. However, in the meta-analysis of Bowling et al. (2015) perceived workload did not significantly correlate with a broad measure of task performance $(\mathrm{k}=16$, $\left.r_{c}=-.03\right)$. In contrast, Szalma et al. (2008) used a larger sample of intervention studies $(k=125)$ and examined type of task and type of performance measure more closely. They found that time pressure increased work speed $\left(.12<\mathrm{r}_{\mathrm{c}}<.28\right)$ and reduced task accuracy $\left(-.16<\mathrm{r}_{\mathrm{c}}<-.32\right)$ in tasks with perceptual and cognitive demands. For motor tasks time pressure reduced work speed $\left(\mathrm{r}_{\mathrm{c}}=-.29\right)$. Thus, assuming that supplementary rest breaks might actually increase work intensity, beneficial but also detrimental effects on task performance might develop.

Interruptions. As outlined above a rest break is, by definition, an interruption of the workflow. Some studies reported that employees perceive frequently scheduled short rest breaks as disruptive and impairing events (Dababneh et al. 2001; Henning et al. 1997) because (sub-) goals cannot be reached. Work interruptions increase mental and emotional strain and impair mental recovery from work (Baethge et al. 2015). However, effects of interruptions on task performance are more complex (Baethge et al. 2015). Few interruptions increase activation and effort investment resulting in higher task performance. However, after a certain threshold of cumulating interruptions, task execution is severely impaired and, thus, performance will decrease. This is also in line with findings from Graf (1922) suggesting an inverse u-shaped pattern between total working time and total rest break duration for task performance. Notably, results of Graf's lab studies revealed that rest breaks with a length of 5 to $10 \%$ of total working time are 'worthwhile'.

Loss of practice and motivation. After a rest break performance might temporarily decrease. Such a warm-up decrement has been explained by a loss of practice and motivation (Adams 1961; Graf 1927; Rivers/Kraepelin 1896). However, at least for motor tasks this effect decreases after a few days due to improvements in motor skills (Rutenfranz/Iskander 1966).

\section{The Present Study}

Based on these insights, the aim of this study was to investigate the impact of within-shift, supplementary short rest breaks that are externally scheduled in advance on measures of task 
performance. More specifically, our major question is whether such rest breaks compensate the associated loss of potentially productive working time. We use meta-analysis to quantitatively review the strength of evidence from current research. Moreover, we will also explore effects of potential moderating variables such as study and sample characteristics, task characteristics, and characteristics of the rest break schedule.

\section{Methods}

We conducted a meta-analysis to answer our research questions. Below, we describe the literature search, the coding procedure, and the meta-analytic computations.

\section{Literature Search and Study Inclusion}

Our literature search follows the four-step approach according to the PRISMA statement (Moher et al. 2009) which are identification and screening of studies, checking their eligibility, and, finally, study inclusion.

\section{Identification}

At first, we conducted a search of German and English studies in scholarly literature databases (EBSCO, PubMed, PSYNDEX, SCOPUS) for the years January 1990 to December 2014. We selected this time period to find studies that are representative concerning the present work situation and sample characteristics. An initial search with relatively broad search terms (e.g., rest, break, pause) yielded over one million results. Thus, we developed a search string with about 200 German and English word combinations (i.e., "work break" OR "rest break"; the complete search string can be requested from the first author of this paper) that was combined with a work context string (work ${ }^{*}$ OR occupation ${ }^{\star} \mathrm{OR}_{\text {job }}{ }^{\star}$ or employ ${ }^{\star}$ OR drive ${ }^{\star}$ ) and an exclusion string (i.e., "pregnant" OR "school”). This initial search yielded 9,259 studies. In addition, a further free hand search yielded 530 studies. After removing duplicates 8,350 studies remained.

\section{Screening}

Next, we checked the thematic fit of the titles and abstracts for the remaining studies, i.e., the study investigated rest breaks. Interrater reliability of coding for a subsample of 100 randomly selected studies was good (two raters; $\kappa=.70 ; 95 \%$ CI $[.52 ; .89]$ ). The first two authors discussed reasons for differences in study coding (nine of 100 studies) and harmonized decision criteria for the full screening sample. Finally, we excluded 7,301 studies after screening (main reasons: earlier editions of book chapters, Non-German or Non-English publication, editorials, not about within-shift breaks).

\section{Eligibility}

We checked $\mathrm{k}=1,049$ full-text articles for inclusion. We used the following criteria for study inclusion: (a) (quasi-)experimental comparison (between-subject or within-subject design) between a condition with within-shift, supplementary short rest breaks and a control condi- 
tion without, (2) at least two supplementary short rest breaks were implemented, (3) the length of short rest breaks was stable over the shift or total working time and between 3 and 10 minutes (Richter/ Hacker 2014), (4) the start and end of these rest breaks were externally scheduled (i.e., not by the participants), (5) measures of task performance were assessed, (6) the author(s) reported sufficient data to calculate an effect size measure and its standard error. For instance, we excluded the study of Dababneh et al. (2001) that was cited in two prior reviews (Tucker 2003; van Holland et al. 2015) as information on productivity was only reported for the final shift period. Moreover, we found a difference of more than three standard deviations between the estimated effect size and the mean in our final sample, indicating it as outlier. We also excluded studies that relied on rest breaks in a sport or educational context. Within this stage, we identified ten systematic narrative reviews about effects of rest breaks. Accordingly, we checked the cited references. However, this yielded no further studies. Altogether, we excluded $\mathrm{k}=1,039$ studies, which left ten publications for inclusion.

\section{Inclusion}

In our meta-analysis, we finally combined data from $\mathrm{k}=11$ independent study samples $(\mathrm{N}=$ 705; see Table 1 for an overview)

\section{Coding Procedure}

\section{Effect size estimation}

We used Hedges' g (Hedges/Olkin 1985) for effect size estimation as many studies had small total sample sizes (Median $=42$; Borenstein et al. 2009). For repeated-measurement (withinsubject or crossover) designs, we considered the published lagged correlation of measures or, if not reported, estimated this with a conservative value of $r=.50$ (see meta-analysis of Sturman et al. 2005). To ensure independence of effect sizes, we used average effect size estimates for studies that reported multiple performance measures. In such cases, we considered their dependence and corrected variances as outlined by Borenstein et al. (2009). For studies investigating multiple rest break interventions (e.g., manipulation of rest break length) conditional effect sizes were combined for the overall analyses and used separately for moderator analyses.

The first author conducted all effect size calculations and double-checked them. Inconsistencies were discussed and resolved with the second author.

\section{Coding of performance measures}

We recorded effect sizes for quality and quantity measures of task performance. Quality variables were measures of accuracy (errors, error rate). One study examined rest breaks of doctors during surgery. For this study, we coded the number of critical intraoperative events and the urine production of patients as quality measures (see Engelmann et al. 2011, 2012). Quantity variables were measures representing the amount of work performed in a specific time period (e.g., productivity rate during farm work, number of calls in call-center work, number of key strokes for data-entry work). All performance measures were objectively measured. 
Table 1: Characteristics of studies included in the meta-analysis

\begin{tabular}{|c|c|c|c|c|c|c|}
\hline & $\begin{array}{l}\text { Sample size, } \\
\text { sample, country }\end{array}$ & $\begin{array}{l}\text { Mean age, } \% \\
\text { females }\end{array}$ & $\begin{array}{l}\text { Setting, design, } \\
\text { intervention length } \\
\text { (days) }\end{array}$ & $\begin{array}{l}\text { Task demands, } \\
\text { working time } \\
\text { (minutes) }\end{array}$ & $\begin{array}{l}\text { Rest break } \\
\text { schedule }^{\mathrm{a}}\end{array}$ & $\begin{array}{l}\text { Effect size esti- } \\
\text { mates ( } g, S E) \text {, } \\
\text { number of out- } \\
\text { come variables }\end{array}$ \\
\hline $\begin{array}{l}\text { Engelmann et al. } \\
(2011,2012)\end{array}$ & $\begin{array}{l}\mathrm{N}=7 \text {, employees, } \\
\text { Germany }\end{array}$ & N.A., $17 \%$ & Field, WS-R, 4 & mixed, 180 & $0,25,5,25,5,14$ & $\begin{array}{l}\text { QA: } 0.08,0.28,1 \\
\text { QL: } 0.45,0.24,2\end{array}$ \\
\hline $\begin{array}{l}\text { Faucett et al. (2007, } \\
\text { Study 1) }\end{array}$ & $\begin{array}{l}\mathrm{N}=66, \text { employ- } \\
\text { ees, US }\end{array}$ & $25,21 \%$ & Field, BS-R, 2 & physical, 480 & $50,20,5,60,4,4$ & QA: $-0.04,0.24,1$ \\
\hline $\begin{array}{l}\text { Faucett et al. (2007, } \\
\text { Study 2) }\end{array}$ & $\begin{array}{l}\mathrm{N}=32 \text {, employ- } \\
\text { ees, US }\end{array}$ & $41,72 \%$ & Field, BS-R, 3 & physical, 480 & $50,20,5,60,4,4$ & QA: $-0.17,0.25,1$ \\
\hline $\begin{array}{l}\text { Galinsky et al. } \\
(2000)\end{array}$ & $\begin{array}{l}\mathrm{N}=42 \text {, employ- } \\
\text { ees, US }\end{array}$ & $30,74 \%$ & Field, WS-R, 20 & mental, 450 & $60,20,5,60,4,4$ & QA: $-0.04,0.13,2$ \\
\hline $\begin{array}{l}\text { Galinsky et al. } \\
\text { (2007) }\end{array}$ & $\begin{array}{l}\mathrm{N}=51 \text {, employ- } \\
\text { ees, US }\end{array}$ & $36,92 \%$ & Field, WS-R, 20 & mental, 450 & $60,20,5,60,4,4$ & QA: $0.20,0.13,2$ \\
\hline $\begin{array}{l}\text { Henning et al. } \\
\text { (1997, Study 1) }\end{array}$ & $\begin{array}{l}\mathrm{N}=34 \text {, employ- } \\
\text { ees, US }\end{array}$ & $26,89 \%$ & Field, BS-R, 20 & mental, 450 & $60,12,3,60,4,3$ & QA: $0.00,0.35,1$ \\
\hline $\begin{array}{l}\text { Henning et al. } \\
\text { (1997, Study 2) }\end{array}$ & $\begin{array}{l}\mathrm{N}=10 \text {, employ- } \\
\text { ees, US }\end{array}$ & $25,79 \%$ & Field, WS-NR, 15 & mental, 450 & $60,12,3,60,4,3$ & QA: $0.41,0.27,1$ \\
\hline $\begin{array}{l}\text { Claus/Willamowski } \\
\text { (2002), Hüttges et } \\
\text { al. (2005) }\end{array}$ & $\begin{array}{l}\mathrm{N}=19 \text {, employ- } \\
\text { ees, Germany }\end{array}$ & N.A., $90 \%$ & Field, WS-NR, 5 & mental, 450 & $\begin{array}{l}\text { Trial A: } 30,60,5 \text {, } \\
25,12,13 \text {; Trial B: } \\
30,60,10,50,6 \text {, } \\
13\end{array}$ & QA: $-0.05,0.19,1$ \\
\hline $\begin{array}{l}\text { Paulus et al. (2006, } \\
\text { Study 2) }\end{array}$ & $\begin{array}{l}\mathrm{N}=107, \text { students, } \\
\text { US }\end{array}$ & 27, N.A. & Lab, BS-R, 1 & mental, 30 & $0,6,3,10,2,20$ & QA: $0.41,0.17,2$ \\
\hline $\begin{array}{l}\text { Paulus et al. (2006, } \\
\text { Study 3) }\end{array}$ & $\begin{array}{l}\mathrm{N}=104, \text { students, } \\
\text { US }\end{array}$ & 27, N.A. & Lab, BS-R, 1 & mental, 30 & $0,6,3,10,2,20$ & QA: $0.12,0.17,2$ \\
\hline $\begin{array}{l}\text { Van den Heuvel et } \\
\text { al. (2003) }\end{array}$ & $\begin{array}{l}\mathrm{N}=233 \text {, employ- } \\
\text { ees, Netherlands }\end{array}$ & $39,48 \%$ & Field, BS-R, 36 & mental, 390 & $30,40,5,35,8,10$ & $\begin{array}{l}\text { QA: } 0.21,0.14,1 \\
\text { QL: } 0.18,0.12,3\end{array}$ \\
\hline
\end{tabular}

Note: $\mathrm{N}=$ sample size, $\mathrm{g}=$ Hedges $\mathrm{g}, \mathrm{SE}=$ standard error of $\mathrm{g}$, N.A. = no information available, $\mathrm{WS}=$ within-subject design, $\mathrm{BS}=$ betweensubject design, $\mathrm{R}=$ randomized trial, $\mathrm{NR}=$ non-randomized trial, $\mathrm{QA}=$ quantitative task performance, $\mathrm{QL}=$ qualitative task performance. a Total time for longer breaks in minutes, total time for supplementary short rest breaks in minutes, length of short rest breaks in minutes, rest break interval in minutes, number of supplementary short rest breaks (rest break frequency), time loss due to supplementary short rest breaks in \%.

\section{Coding of moderator variables}

We assessed several moderating variables related to characteristics of the samples and studies, the tasks, and the rest break schedules.

Sample and study characteristics. We recorded data about the samples' mean age in years, the percentage of females in the samples, the type of sample (employees vs. students), the study location (US vs. Europe vs. others), the study setting (field study vs. lab study), the study design (between-subject vs. within-subject), and the randomization of participants (with vs. without randomization). Furthermore, we coded the length of interventions in days.

Task characteristics. The total working time in minutes and the predominant type of task demands (mental vs. physical vs. mixed) according to task descriptions in the study were coded.

Rest break characteristics. The total time for additional longer breaks, the total time for short rest breaks, the time for single short rest breaks, the frequency of short rest breaks, the rest break interval, two indicators for the relative work-to-rest-ratio (i.e., total working time divided by (a) the total time for all rest breaks and (b) the total time for short rest breaks) was 
recorded. Moreover, we calculated the time reduction due to supplementary rest breaks in percent (i.e., total time for short rest breaks relative to the total working time).

\section{Meta-analytic computations}

We used a stepwise approach for the meta-analytic computations. First, we checked our data for potential outliers. We found no extreme values differing more than two standard deviations from the mean. Thus, we included all data for further calculations. Second, we ran a random-effects model to calculate pooled effect sizes (Borenstein et al. 2009; Hedges/Vevea 1998). In our meta-analysis, we only corrected for sampling error. We report $\mathrm{k}$ as the number of studies for effect size estimation, $\mathrm{N}$ as the sum of individuals for $\mathrm{k}$ studies, pooled Hedges's $g$ as effect size estimate, and the $95 \%$ confidence interval (CI) for g. If the $95 \% \mathrm{CI}$ excludes zero, the effect size estimate is significant from zero with $\mathrm{p}<.05$ (two-tailed).

In addition, we report indices for heterogeneity indicating between study variations of true effect sizes. To quantify heterogeneity, we report the $\mathrm{Q}_{\mathrm{Within}}$ and $\mathrm{I}^{2}$-statistics. If $\mathrm{Q}_{\text {within }}$ is significant or $\mathrm{I}^{2}$ is higher $25 \%$ we regard effect sizes as heterogeneous. In contrast to the Q-statistics, $\mathrm{I}^{2}$ is not sensitive to the number of aggregated studies. However, it cannot be used for testing significance of heterogeneity. Thus, both measures should be used to analyze heterogeneity. A substantial amount of heterogeneity indicates the impact of moderating variables (Borenstein et al. 2009). For categorical moderators, we applied random effects subgroup analyses

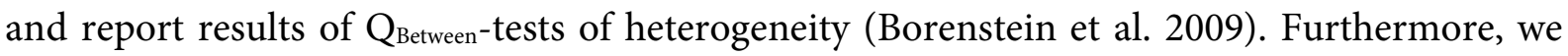
used random effects meta-regression (unrestricted maximum likelihood method) for metric moderators. We conducted these analyses according to the procedures and recommendations proposed by Borenstein et al. (2009).

We conducted effect size estimation and all further analyses with Comprehensive MetaAnalysis (CMA) software 2.2 (2010, Biostat, Inc, Englewood, NJ). We considered effect sizes around 0.2 as small effect, around 0.5 as medium effect, and around 0.8 or higher as large effect (Cohen 1992). Moreover, we used the U3 index to calculate relative improvement rates in task performance in percent (Lipsey/Wilson 2001). Finally, we examined the chance that a publication bias might have affected our results with funnel plot analyses, Eggers' regression test, and the trim and fill method (see Borenstein et al. 2009).

\section{Results}

\section{Sample and Study characteristics}

The mean age of employees was 30.6 years and the mean percentage of females in the studies was $64 \%$. Most of the samples were from the US $(\mathrm{k}=8)$, the others from Europe. Only two studies were lab studies. Both studies were the only ones with student samples. The median for the length of one single short rest break was five minutes (range: three to ten minutes), the median for rest break frequency was four times per shift, and the median for the rest break interval was 55 minutes. The median of total working time was 450 minutes. Mean working 
time reduction due to supplementary short rest breaks was about $9.3 \%$ of the total working time. In most studies $(\mathrm{k}=8)$ participants had time for further longer breaks ( $\mathrm{M}=36$ minutes).

In most studies $(\mathrm{k}=8)$ participants performed rather mentally demanding tasks such as office work, brainstorming tasks, or data entry. Two studies examined rest breaks in more physically demanding farm work. One study examined doctors during surgery which is characterized by a mixture of high mental and physical demands.

\section{Effects of Supplementary Short Rest Breaks on Task Performance}

The effect of supplementary short rest breaks on quantity measures of task performance was positive and significant with $\mathrm{g}=0.12(95 \% \mathrm{CI}[0.02,0.23], \mathrm{k}=11, \mathrm{~N}=705,18$ combined effect sizes). This effect can be considered as negligible small or an improvement of 5\%. Effect sizes were homogeneous $\left(\mathrm{Q}_{\text {Within }}(10)=9.20, \mathrm{p}=.513, \mathrm{I}^{2}=0 \%\right)$.

Furthermore, we found a significantly positive effect of supplementary short rest breaks on quality measures of task performance with $\mathrm{g}=0.23(95 \% \mathrm{CI}[0.02,0.45], \mathrm{k}=2, \mathrm{~N}=240$, eight combined effect sizes). This effect can be considered as small or as an improvement of $9 \%$. Effect sizes were homogeneous ( $\left.\mathrm{Q}_{\text {within }}(1)=1.04, \mathrm{p}=.309, \mathrm{I}^{2}=3.4 \%\right)$.

Effect sizes estimates of both performance measures did not differ significantly $\left(\mathrm{Q}_{\text {Between }}(1)=0.79, \mathrm{p}=.374\right)$.

\section{Moderator Analyses}

Although our results suggest that effects sizes were homogenous, results of these heterogeneity analyses should be interpreted with caution. First, under conditions that the number of studies is low, the Q-statistic suffers from problems of low statistical power (Higgins et al. 2003). Second, Borenstein et al. (2009) note that if studies' effect size estimates have low precision (see Forest plots in Figure 1), heterogeneity can be masked and therefore resulting in estimates of $\mathrm{I}^{2}$ near zero. For instance, 95\% uncertainty intervals for $\mathrm{I}^{2}$ (see Borenstein et al. 2009 for the formulas) were 0 to $57 \%$ for quantity measures of task performance. Therefore, we examined the potential impact of further moderating variables. Due to sample size restrictions this was only possible for quantity measures of task performance as outcome. Table 2 shows the results of these moderator analyses.

\section{Sample and Study characteristics}

Effect sizes were independent of samples' mean age, samples' percentage of females, type of sample, and sample size.

Moreover, we found no significant moderating impact of study location, study setting, study design, and randomization procedure. The pooled effect size in studies using a randomized control-group design was $\mathrm{g}=0.16,95 \% \mathrm{CI}[-0.01,0.32]$. Length of intervention had no linear moderating effect. Since one early study reported u-shaped effects (Vernon 1925), we ran a further subgroup analysis (intervention length: one day vs. two to five days vs. more than five days). There were still no significant subgroup differences $\left(Q_{\text {Between }}(2)=3.64, p=.162\right)$. However, on a descriptive level such an u-shaped pattern of intervention length was indicated 
(one day: $\mathrm{k}=2, \mathrm{~g}=0.26,95 \% \mathrm{CI}[0.03,0.50]$; two to five days: $\mathrm{k}=4, \mathrm{~g}=-0.05,95 \% \mathrm{CI}[-0.28,0.18]$; more than five days: $\mathrm{k}=5, \mathrm{~g}=0.14,95 \% \mathrm{CI}[-0.00,0.28]$ ).

Figure 1: Forest plots for quality and quantity measure of task performance

\section{Hedges' $\mathrm{g}$ and $95 \% \mathrm{CI}$}

\section{Performance-Quality}

Van den Heuvel et al. (2003)

Engelmann et al. $(2011,2012)$

Performance-Quantity

Faucett et al. (2007), Study 2

Hüttges et al. (2005)

Galinsky et al. (2000)

Faucett et al. (2007), Study 1

Henning et al. (1997), Study 1

Engelmann et al. $(2011,2012)$

Paulus et al. (2006), Study 3

Galinsky et al. (2007)

Van den Heuvel et al. (2003)

Paulus et al. (2006), Study 2

Henning et al. (1997), Study 2
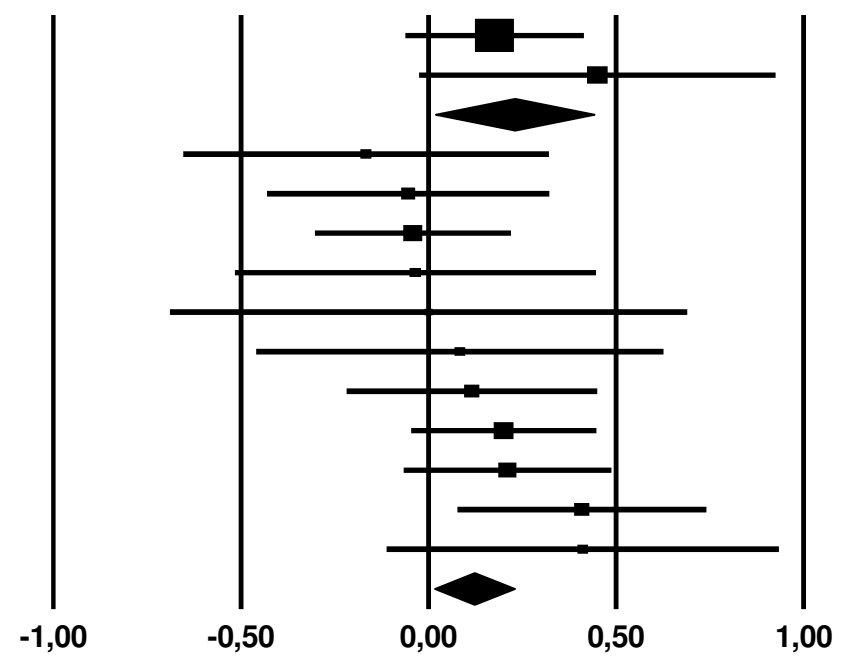

Note: Trapezoid symbols represent mean effect size estimates. Thickness of boxes represents the study weight.

\section{Task characteristics}

We found no significant moderating effects of total working time and task demands.

\section{Rest break schedule}

Finally, we examined several characteristics of the rest break schedules. First, we found no moderating impact of total time for further longer breaks and total time for short rest breaks. Furthermore, time for single short rest breaks, frequency of short rest breaks, and rest break interval were no significant moderating variables.

To account for between-study differences in total working time, we conducted some further analyses. However, also relative work-to-rest-ratios were no significant moderating variables.

Moreover, we found no moderating effect of time reduction due to supplementary rest breaks. 
Table 2: Results of moderator analyses for performance quantity as outcome

\begin{tabular}{|c|c|c|c|c|c|c|c|}
\hline \multirow[b]{2}{*}{ Moderator } & \multicolumn{7}{|c|}{$95 \% \mathrm{CI}$} \\
\hline & $\mathrm{k}$ & $\mathrm{N}$ & & $\mathrm{PE}$ & $\mathrm{LL}$ & UL & Difference test \\
\hline \multicolumn{8}{|c|}{ Study and sample characteristics } \\
\hline Mean age & 9 & 679 & $\mathrm{~b}$ & -0.03 & -0.02 & 0.02 & \\
\hline Females [\%] & 9 & 494 & $\mathrm{~b}$ & 0 & -0.005 & 0.005 & \\
\hline Study sample & & & & & & & $\mathrm{Q}(1)=1.73, \mathrm{p}=.189$ \\
\hline Students & 2 & 211 & g & 0.26 & 0.03 & 0.5 & \\
\hline Employees & 9 & 494 & g & 0.09 & -0.03 & 0.21 & \\
\hline Sample size & 11 & 705 & $\mathrm{~b}$ & 0.001 & -0.001 & 0.002 & \\
\hline Study location & & & & & & & $\mathrm{Q}(1)=0.02, \mathrm{p}=.902$ \\
\hline US & 8 & 446 & g & 0.13 & 0 & 0.25 & \\
\hline Europe & 3 & 294 & g & 0.11 & -0.1 & 0.32 & \\
\hline Study setting & & & & & & & $\mathrm{Q}(1)=1.73, \mathrm{p}=.189$ \\
\hline Field & 9 & 494 & g & 0.09 & -0.03 & 0.21 & \\
\hline Lab & 2 & 211 & g & 0.26 & 0.03 & 0.5 & \\
\hline Study design & & & & & & & $\mathrm{Q}(1)=0.41, \mathrm{p}=.524$ \\
\hline Between-subject & 6 & 576 & g & 0.16 & 0.01 & 0.31 & \\
\hline Within-subject & 5 & 129 & g & 0.09 & -0.06 & 0.24 & \\
\hline Randomization & & & & & & & $\mathrm{Q}(1)=0.02, \mathrm{p}=.902$ \\
\hline Randomized & 9 & 676 & g & 0.13 & 0.01 & 0.24 & \\
\hline Nonrandomized & 2 & 29 & g & 0.11 & -0.2 & 0.41 & \\
\hline Intervention length & 11 & 705 & $\mathrm{~b}$ & 0.002 & -0.01 & 0.01 & \\
\hline \multicolumn{8}{|c|}{ Task characteristics } \\
\hline Total working time & 11 & 705 & $\mathrm{~b}$ & -0.001 & -0.0001 & 0.0001 & \\
\hline Task demands & & & & & & & $\mathrm{Q}(2)=1.89, \mathrm{p}=.389$ \\
\hline Mental & 8 & 600 & g & 0.15 & 0.04 & 0.27 & \\
\hline Physical & 2 & 98 & g & -0.1 & -0.44 & 0.24 & \\
\hline Mixed & 1 & 7 & g & 0.08 & -0.46 & 0.63 & \\
\hline \multicolumn{8}{|c|}{ Characteristics of rest break schedule } \\
\hline Time longer breaks (total) & 11 & 705 & $\mathrm{~b}$ & -0.002 & -0.007 & 0.002 & \\
\hline Time short breaks (total) & 11 & 705 & $\mathrm{~b}$ & -0.004 & -0.01 & 0.003 & \\
\hline Time short break & 11 & 705 & $\mathrm{~b}$ & -0.06 & -0.13 & 0.006 & \\
\hline Frequency short breaks & 11 & 705 & $\mathrm{~b}$ & -0.01 & -0.05 & 0.03 & \\
\hline Rest break interval & 11 & 705 & $\mathrm{~b}$ & -0.004 & -0.008 & 0.002 & \\
\hline \multicolumn{8}{|l|}{ Relative work-rest-ratio } \\
\hline Total rest break time & 11 & 705 & $\mathrm{~b}$ & -0.1 & -0.28 & 0.08 & \\
\hline Total short break time & 11 & 705 & $\mathrm{~b}$ & -0.003 & -0.01 & 0.008 & \\
\hline Time reduction [\%] & 11 & 705 & b & 0.009 & -0.008 & 0.003 & \\
\hline
\end{tabular}

Note: $\mathrm{k}=$ number of studies, $\mathrm{N}=$ total sample size, $\mathrm{PE}=$ point estimate of effect sizes measure, $\mathrm{CI}=$ confidence interval of effect size measure, $\mathrm{LL}=$ lower limit, $\mathrm{UL}=$ upper limit, $\mathrm{g}=$ Hedges $\mathrm{g}, \mathrm{b}=$ unstandardized regression weight. 


\section{Supplementary Analyses}

\section{Publication bias}

A meta-analysis might yield inaccurate effect size estimates if results rely on an incomplete sample of relevant studies. Below, we report results of some supplementary analyses investigating such a potential publication bias. To perform such analyses with CMA at least three studies are needed. Thus, these analyses were only possible for quantity measures of task performance.

First, we inspected the funnel plot where standard errors and effect size estimates of all studies are plotted against each other. An asymmetrical distribution of effect sizes indicates such a bias. However, after inspecting the graph, we rejected this assumption.

Second, results of Egger's regression test (Egger et al. 1997) revealed no statistical asymmetric effect size distribution $(b=-0.52,95 \%$ CI $[-2.77,1.73])$.

Third, we applied a random effects trim and fill model (Duval/Tweedie 2000). In such a model, pooled effect sizes are recomputed until the funnel plot is symmetric by adding effect sizes from hypothetical missing studies. Results of this analysis yielded one potential leaving study with a positive effect size estimate. The pooled effect size estimate for quantity measures of task performance did only marginally change $(\mathrm{g}=0.14,95 \% \mathrm{CI}[0.03,0.25])$ and remained positive and significant.

Thus, according to these results the likelihood that a publication bias might have affected our results is relatively low.

\section{Consequences of mental and physical strain}

Supplementary short rest breaks reduce total working time. We found that such rest break schedules improve mean quantitative task performance. Hence, it can be argued that supplementary short rest breaks increase work demands as the work has to be done in less time. Accordingly, persons might have to invest compensatory effort for goal-attainment at costs of higher negative short-term strain consequences (Hockey 1997; Meijman/Mulder 1998). We examined this assumption in our sample of studies and added further effect size information from the study of Dababneh et al. (2001). We coded intervention effects of supplementary short rest breaks on measures of short-term consequences of self-reported mental strain (e.g., fatigue, positive and negative affect, monotony, stress experience, mental effort) and selfreported physical strain (e.g., physical discomfort in different body areas). Negative effect sizes represent lower negative strain consequences.

We found that supplementary short rest breaks significantly decreased negative strain consequences. Pooled effect sizes were $\mathrm{g}=-0.20$ (95\%CI $[-0.38,-0.03], \mathrm{k}=9, \mathrm{~N}=296)$ for mental strain outcomes and $\mathrm{g}=-0.36(95 \% \mathrm{CI}[-0.58,-0.14], \mathrm{k}=10, \mathrm{~N}=529)$ for physical strain outcomes. Both effect sizes are small. For both outcomes heterogeneous effect sizes were indicated (mental strain: $\mathrm{Q}_{\text {Within }}(8)=11.43, \mathrm{p}=.179, \mathrm{I}^{2}=30.0 \%$; physical discomfort: $\mathrm{Q}_{\text {Within }}(9)=36.54$, $\left.\mathrm{p}<.001, \mathrm{I}^{2}=75.4 \%\right)$. Funnel plot inspection and results of further statistical tests did not indicate a publication bias. Overall, these results do not support the assumption that supplementary short rest breaks increase quantitative task performance at costs of higher negative shortterm strain consequences. 


\section{Discussion}

Results of several prior reviews suggest that within-shift rest breaks are important to protect employees' well-being, health, and work safety (Ariens et al. 2001; Barredo/Mahon 2007; Brewer et al. 2006; da Costa/Vieira 2008; Folkard/Lombardi 2006; Goodman et al. 2012; Griffiths et al. 2007; van Holland et al. 2015; Kennedy et al. 2010; Nachreiner et al. 2010; Tucker 2003). However, less is known whether a managerial investment in more paid time for rest breaks also pays off by improving employees' task performance. Thus, the aim of our metaanalysis was to uncover the impact of supplementary short rest breaks on quantity and quality measure of task performance. To answer this question, we aggregated data from 11 independent study samples.

\section{Theoretical Implications}

The overall effect sizes of supplementary short rest breaks on task performance measures were significantly positive. More specifically, a mean reduction of about $9.3 \%$ daily working time for further rest breaks increased employees' quantitative task performance for about $5 \%$ and their work quality for about $9 \%$.

Our results support findings of prior studies revealing that schedules with fixed supplementary short rest breaks do not decrease (Galinsky et al. 2000; Henning et al. 1997) but rather increase (Dababneh et al. 2001) task performance. Our meta-analytic findings revealed that beneficial effects of supplementary frequent short rest breaks on task performance are rather small. However, at least with regard to effects on quantitative task performance, we should not forget that individuals outperformed a reduction of potentially productive working time.

Several lines of reasoning have been discussed to explain increases in task performance by fixed schedules of supplementary short rest breaks. Referring to the seminal work of Graf $(1922,1927)$ improvements in task performance develop if effects of several beneficial mechanisms connected to rest breaks (e.g., recovery from and prevention of negative short-term strain consequences, optimal effort investment, less time for unofficial breaks and unnecessary tasks) exceed effects of accompanying impairing mechanisms (e.g., interruption of work flow, loss of motivation). Thus, according to our results beneficial effects of scheduled short rest breaks seem to prevail. This is also supported by one further finding of our study: Rest breaks significantly improved individuals' self-reported short-term mental and physical wellbeing. This suggests no adverse compensatory costs of work intensification due to reduced working time (Hockey 1997; Meijman/Mulder 1998) which has been also shown earlier for machine-paced in contrast to self-paced work (Graf 1930). However, we could not disentangle the interplay of the assumed rest break mechanisms more precisely. For instance, the latter effect on strain outcomes might be due to successful recovery from impairing strain effects during rest breaks and/or lower total load because of reduced working time. Thus, future studies should examine the proposed mediating variables in combination to shed light on the hitherto "black box". 
Along these lines a further question concerns the importance of rest breaks for job design. From a theoretical point of view both the Effort-Recovery Model (Meijman/Mulder 1998) and the Motivational Control Theory of Cognitive Fatigue (Hockey 1997, 2011) suggest that rest breaks and task changes reduce impairing short-term effects of strain. Accordingly, task performance should increase when interruption periods represent a change from task demands. Thus, some previous experimental lab studies found rest breaks and task changes were both effective for improving task performance (Bennett et al. 1974; Sio/Ormerod 2009). According to ergonomic principles in the design of work systems (e.g., DIN EN ISO 6385 2004) task changes should be favored as primary preventive strategy over rest breaks (i.e., secondary prevention) as they increase task variety, learning opportunities, and individuals' skill use. Thus, certainly, there is a strong need for field studies investigating effects of both interventions, also for other strain-related outcome variables, and also in combination. The latter point is important because in our meta-analysis we found several studies on duties with high task variety (e.g., office work, surgeons, and brainstorming) where supplementary rest breaks additionally improved task performance and well-being.

We further investigated the impact of several moderating variables such as sample characteristics (age, gender, profession), study characteristics (sample size, study location, study design, randomization procedure), task characteristics (working time, task demands), and rest break characteristics (total time for rest breaks of different length, rest break frequency, rest break interval, work-to-rest ratios, time reduction due to supplementary rest breaks, and length of intervention). In this sample of studies, none of these moderator tests were significant for quantitative task performance as outcome. As our moderator analyses relied on modest samples of substudies, low statistical power might be a limitation. However, our analyses revealed homogeneous effect sizes for both performance measures. This rather suggests no further impact of moderating variables here, but might also base on variance restrictions in the primary studies. However, at least some experimental studies found that schedule characteristics affect task performance (e.g., Balci/Aghazadeh 2003; Bhatia/Murrell 1969). Therefore, future research should examine moderating variables more systematically and also in combination (e.g., different rest break schedules for task with different demands).

\section{Limitations and Future Research Directions}

What are potential limitations of our study? First, the scope of our literature search was limited concerning the time period of publications (1990 to 2014) and language (studies published in German or English). However, after a series of analyses, we found no support for a potential publication bias. Importantly, pooled effect size estimates should be interpreted with caution as in our meta-analysis the number of combined study results and also the sample size, especially for qualitative task performance measures, was limited. We further note that generalization of results to different working conditions might be limited. For instance, most studies were conducted in the US and with jobs or tasks that are mental demanding. Moreover, in most studies short rest breaks were added to further longer breaks. However, this is also a strength of our study, since nowadays such working conditions cover a wide and increasing range of jobs in industrialized countries. 
A second limitation concerns the estimation of lagged correlations for performance measures in within-subject designs and, moreover, intercorrelations of multiple performance measures within single studies. However, this procedure does not affect pooled effect size estimates but rather their precision (Borenstein et al. 2009). As our approach here was rather conservative, significant effects of rest breaks on task performance are even more impressive.

Third, all intervention periods were relatively short. An early study of Vernon (1925) found that performance effects of rest breaks followed an u-shaped pattern with time and an increase of effects after 11 weeks. We found no significant moderating effect of intervention length but descriptive data indicated such an u-shaped pattern. In our review the longest rest break intervention was eight weeks (van den Heuvel et al. 2003). Thus, reported direct effect sizes for supplementary short rest breaks might be rather conservative and more research is necessary to evaluate rest break interventions over longer periods, also to uncover more longterm effects on performance and strain outcomes.

Fourth, at least some studies reported that a certain percentage of participants skipped their supplementary rest breaks, also as they feared a loss of productivity and conflicts with productivity goals (Henning et al. 1997; Rutenfranz/Stoll 1966, van den Heuvel et al. 2003). Between-study variance in compliance rate might have biased our results. Unfortunately, compliance was poorly documented in the studies. Thus, we would like to encourage the authors of future studies to mandatory report such measures.

Fifth, in our meta-analysis we only considered studies investigating fixed rest break schedules. Prior studies found individuals' recovery from strain might be less successful under selfscheduled rest breaks (Tucker 2003). However, two field studies (Claus/Willamowski 2002; McLean et al. 2001) and four lab studies (Hahn 1989; Karwowski et al. 1994; Praetsch 2013; Schmatz/Klingebiel 2012) found no significant effect of timing control on task performance. One lab study found a significantly higher task performance under self-scheduled than fixed rest breaks (Ho 2008) whereas O’Donnell and colleagues (2015) report a significant inverse pattern. However, short intervention periods and small study sample sizes limit interpretation of these results. Moreover, the additional moderating impact of work-rest-sequences is unknown so far. Therefore, future studies should also examine timing control as independent variable, stratified for different work-rest-patterns, when disentangling effects of supplementary short rest breaks on task performance.

Finally, several other rest break characteristics were less well documented and examined in the studies. This concerns individuals' rest break activities (e.g., relaxation or physical activities), physical conditions at the rest break location, and, most importantly, the quality, intensity, and temporal dynamics of work demands. Future studies need to examine these variables as moderators as they might additionally influence recovery processes (Trougakos/Hideg 2009; Tucker 2003).

\section{Practical Implications}

As argued in the introduction, sufficient time for within-shift rest breaks is important for employees' well-being, health, and safety. Thus, in most countries over the world national legislation assures employees' to get at least a minimum of mandatory rest break time during the 
working day (McCann 2005). However, in European countries, this only affects employees being on duty for longer than six hours and primarily concerns one or two longer and unpaid rest breaks (e.g., for meals). In agreement with previous work, we found that employees' performance and well-being benefit from more frequently scheduled, supplementary short rest breaks.

Our findings suggest that employers should extend employees' daily within-shift recovery time by supplementary and frequently scheduled short rest breaks as they increase task performance and decrease impairing effects of strain over the shift. Moreover, to motivate employees for such additional rest breaks, they should be scheduled as paid working time. It might be counterintuitive for managers, but according to our results this investment in less working time and more recovery time pays off twice, thus, in higher performance output and lower negative strain levels of their employees.

Although not under the scope of this review, there are further recommendations from the literature how to implement such break schedules. For instance, managers should actively improve employees' compliance with such rest breaks. Thus, rest break schedules should be developed in participation with employees, employees should be given the official permission for such breaks, and they should be encouraged and reinforced to take these breaks (Hüttges et al. 2005; Zacher et al. 2014). As short breaks are by definition only of short duration, in most cases employees will take them at their workplace. Thus, stressors that might impede recovery, e.g., noise or heat, should be switched off at this time. If this is not possible, for instance at an industrial assembly line, employees should have opportunities to reach designated rest break areas quickly.

From our results we cannot deduce general rules-of-thumb for timing of optimal rest break schedules (see also Konz 1998; Tucker 2003). According to Bokranz (1985) and Rohmert (1973a,b) rest breaks must be longer with increasing rest break intervals to reach sufficient recovery from impairing consequences of short-term strain. Several authors (Bokranz 1985; Nachreiner et al. 2010; Tucker 2003) argue that the nature of work has to be considered when planning optimal rest break schedules. Thus, the more mental and/or physical demanding the work, the earlier the worker must rest. However, it is also important that employees can finish their task before a break, also to prevent feelings of being interrupted during the work flow. Thus, hourly five minute breaks might be appropriate for work that is repetitive or highly physically or mentally demanding while longer rest breaks after longer periods of work might be better in other jobs (Richter/Hacker 2014; Tucker 2003; Wegge et al. 2014). From a more practical perspective, managers might probe and evaluate different schemes with their employees and select the most optimal one.

Finally, nowadays, in many jobs, especially in the service and healthcare sector, the lack of mandatory longer rest breaks or their premature interruption are very common (LohmannHaislah 2012; Sarna et al. 2009; Wendsche et al. 2014). Actually, employers have to prevent such situations by improving work organization. However, the opportunity for authorized supplementary rest breaks might help employees to get at least a minimum of within-shift recovery time, even on days were work demands impede a longer mandatory rest breaks during the work shift. 


\section{Conclusion}

In our meta-analysis, we reviewed the literature published within the last 25 years on effects of fixed schedules of supplementary short rest breaks on task performance.

Our results indicate that even though such paid rest breaks incorporate a loss of potentially productive working time, they increase task performance and improve mental and physical well-being. Notably, these effects on task performance even existed when short breaks were added to mandatory longer breaks. Therefore, our results reveal that earlier experimental findings from this research (Graf 1922, 1927) are also valid in more complex, modern work systems.

However, our review also uncovered serious gaps in the literature. This concerns the boundary conditions and actual mechanisms for these reported effects, indicating a strong need for further research, especially under improved conceptual conditions.

\section{References}

* Studies included in the meta-analysis are marked with an asterisk.

Adams, J. A. (1961). The second facet of forgetting: A review on warm-up decrement. Psychological Bulletin, 58(4), 257-273.

Amberg, E. (1895). Ueber den Einfluss von Arbeitspausen auf die geistige Leistungsfähigkeit [The impact of rest breaks on mental performance]. Leipzig: Wilhelm Engelmann.

Ariens, G. A., van Mechelen, W., Bongers, P. M., Bouter, L. M. and van der Wal, G. (2001). Psychosocial risk factors for neck pain: a systematic review. American Journal of Industrial Medicine, 39(2), 180-193.

Baethge, A., Rigotti, T. and Roe, R. (2015). Just more of the same, or different? An integrative theoreti$\mathrm{cal}$ framework for the study of cumulative interruptions at work. European Journal of Work and Organizational Psychology, 24(2), 308-323.

Bakker, A. B. and Demerouti, E. (2007). The Job Demands-Resources model: State of the art. Journal of Managerial Psychology, 22(3), 309-328.

Balci, R. and Aghazadeh, F. (2003). The effect of work-rest schedules and type of task on the discomfort and performance of VDT users. Ergonomics, 46(5), 455-465.

Barmack, J. E. (1939). The length of the work period and the work curve. Journal of Experimental Psychology, 25(1), 109-115.

Barredo, R. D. V. and Mahon, K. (2007). The effects of exercise and rest breaks on musculoskeletal discomfort during computer tasks: An evidence-based perspective. Journal of Physical Therapy Science, 19(2), 151-163.

Bennett, C. A., Marcellus, F. S. and Reynolds, J. F. (1974). Counteracting fatigue effects by stimulus change. Proceedings of the Human Factors and Ergonomics Society Annual Meeting, 18(2), 219-224.

Bhatia, N. and Murrell, K. F. (1969). An industrial experiment in organized rest pauses. Ergonomics, $11(2), 167-74$. 
Bokranz, R. (1985). Zur belastungsbegründeten Planung von Erholungspausen: I. Entwurf und Anwendung einer arbeitswissenschaftlichen Theorie der Pausenorganisation. Zeitschrift für Arbeitswissenschaft, 39, 23-30.

Borenstein, M., Hedges, L. V., Higgins, J. P. T. and Rothstein, H. R. (2009). Introduction to MetaAnalysis. Chichester, UK: John Wiley \& Sons, Ltd.

Bowling, N. A., Alarcon, G. M., Bragg, C. B. and Hartman, M. J. (2015). A meta-analytic examination of the potential correlates and consequences of workload. Work \& Stress, 29(2), 95-113.

Brehm, J. W. and Self, E. (1989). The intensity of motivation. Annual Review of Psychology, 40, 109131.

Brewer, S., Van Eerd, D., Amick, B. C., 3rd, Irvin, E., Daum, K. M., Gerr, F., . . Rempel, D. (2006). Workplace interventions to prevent musculoskeletal and visual symptoms and disorders among computer users: A systematic review. Journal of Occupational Rehabilitation, 16(3), 325-358.

Campbell, J. P., McCloy, R. A., Oppler, S. H. and Sager, C. E. (1993). A theory of performance. In: E. Schmitt, W. C. Borman and Associates (Eds.), Personnel selection in organizations (35-70). San Francisco: Jossey-Bass.

${ }^{\star}$ Claus, A. and Willamowski, A. (2002). Kurzpausensysteme im Call-Center [Short rest break schedules in call center work]. Hamburg: Verwaltungs-Berufsgenossenschaft.

Cohen, J. (1992). A power primer. Psychological Bulletin, 112(1), 155-159.

Dababneh, A. J., Swanson, N. and Shell, R. L. (2001). Impact of added rest breaks on the productivity and well being of workers. Ergonomics, 44(2), 164-174.

da Costa, B. R. and Vieira, E. R. (2008). Stretching to reduce work-related musculoskeletal disorders: a systematic review. Journal of Rehabilitation Medicine, 40(5), 321-328.

DIN EN ISO 10075-1 (2000). Ergonomische Grundlagen bezüglich psychischer Arbeitsbelastung - Teil 1: Allgemeines und Begriffe [Ergonomic principles related to mental workload - Part 1: General terms and definitions]. Berlin: Beuth.

DIN EN ISO 10075-2 (2000). Ergonomische Grundlagen bezüglich psychischer Arbeitsbelastung - Teil 2: Gestaltungsgrundsätze [Ergonomic principles related to mental workload - Part 2: Design principles]. Berlin: Beuth.

DIN EN ISO 6385 (2004). Grundsätze der Ergonomie für die Gestaltung von Arbeitsystemen [Ergonomic principles in the design of work systems]. Berlin: Beuth.

Donovan, J. and Radosevich, D. (1999). A meta-analytic review of the distribution of practice effect: Now you see it, now you don't. Journal of Applied Psychology, 84(5), 795-805.

Duval, S. J. and Tweedie, R. L. (2000). Trim and fill: A simple funnelplot-based method of testing and adjusting for publication bias in meta-analysis. Biometrics, 56(2), 455-463.

Egger, M., Smith, G. D., Schneider, M. and Minder, C. (1997). Bias in meta-analysis detected by a simple, graphical test. British Medical Journal, 315, 629-634.

${ }^{\star}$ Engelmann, C., Schneider, M., Grote, G., Kirschbaum, C., Dingemann, J., Osthaus, A. and Ure, B. (2012). Work breaks during minimally invasive surgery in children: patient benefits and surgeon's perceptions. European Journal of Pediatric Surgery, 22(6), 439-444. 
*Engelmann, C., Schneider, M., Kirschbaum, C., Grote, G., Dingemann, J., Schoof, S. and Ure, B. M. (2011). Effects of intraoperative breaks on mental and somatic operator fatigue: a randomized clinical trial. Surgery and Endoscopy, 25(4), 1245-1250.

${ }^{*}$ Faucett, J., Meyers, J., Miles, J., Janowitz, I. and Fathallah, F. (2007). Rest break interventions in stoop labor tasks. Applied Ergonomics, 38(2), 219-226.

Folkard, S. and Lombardi, D. A. (2006). Modeling the impact of the components of long work hours on injuries and "accidents". American Journal of Industrial Medicine, 49(11), 953-963.

Fredrickson, B. L. (2013). Positive Emotions Broaden and Build. In: P. Devine and A. Plant (Eds.), Advances in Experimental Social Psychology (Vol. 47:1-53). Burlington: Academic Press.

${ }^{\star}$ Galinsky, T., Swanson, N., Sauter, S., Dunkin, R., Hurrell, J. and Schleifer, L. (2007). Supplementary breaks and stretching exercises for data entry operators: a follow-up field study. American Journal of Industrial Medicine, 50(7), 519-527.

${ }^{*}$ Galinsky, T., Swanson, N., Sauter, S., Hurrell, J. and Schleifer, L. (2000). A field study of supplementary rest breaks for data-entry operators. Ergonomics, 43(5), 622-638.

Geurts, S. A. and Sonnentag, S. (2006). Recovery as an explanatory mechanism in the relation between acute stress reactions and chronic health impairment. Scandinavian Journal of Work Environment \& Health, 32(6), 482-492.

Goodman, G., Kovach, L., Fisher, A., Elsesser, E., Bobinski, D. and Hansen, J. (2012). Effective interventions for cumulative trauma disorders of the upper extremity in computer users: practice models based on systematic review. Work, 42(1), 153-172.

Graf, O. (1922). Über lohnendste Arbeitspausen bei geistiger Arbeit [Worthwhile rest breaks for mental work]. Psychologische Arbeiten, 7, 548-611.

Graf, O. (1927). Die Arbeitspause in Theorie und Praxis [Rest breaks in theory and practice]. Psychologische Arbeiten, 9, 563-581.

Graf, O. (1930). Untersuchungen über die Wirkung zwangsläufiger zeitlicher Regelungen von Arbeitsvorgängen. I. Beiträge zur Erforschung der Arbeitsbedingungen bei Fließarbeit [Studies on pacing of work. I. Contributions to studying working conditions at assembly line work]. Arbeitsphysiologie, 2, 575-636.

Graf, O., Rutenfranz, J. and Ulich, E. (1970). Arbeitszeit und Arbeitspausen [Working time and rest breaks]. In: A. Mayer and B. Herwig (Eds.), Handbuch der Psychologie, Bd. 9: Betriebspsychologie (2 ed., 244-277). Göttingen: Hogrefe.

Griffiths, K. L., Mackey, M. G. and Adamson, B. J. (2007). The impact of a computerized work environment on professional occupational groups and behavioural and physiological risk factors for musculoskeletal symptoms: a literature review. Journal of Occupational Rehabilitation, 17(4), 743765.

Hahn, E. (1989). Erholungswirkungen ausgewählter Pausenorganisationsvarianten bei Routinebildschirmarbeitstätigkeiten [Recovering effects of different rest breaks schedules at repetitive VDU work]. Zeitschrift für Arbeits- und Organisationspsychologie, 33, 188-196.

Hedges, L. V. and Olkin, I. (1985). Statistical methods for meta-analysis. NY: Academic Press.

Hedges, L.V. and Vevea, J.L. (1998). Fixed and random-effects models in meta-analysis. Psychological Methods, 3, 486-504. 
${ }^{\star}$ Henning, R. A., Jacques, P., Kissel, G. V., Sullivan, A. B. and Alteras-Webb, S. M. (1997). Frequent short rest breaks from computer work: effects on productivity and well-being at two field sites. Ergonomics, 40(1), 78-91.

Higgins, J. P., Thompson, S. G., Deeks, J. J. and Altman, D. G. (2003). Measuring inconsistency in meta-analyses. British Medical Journal, 327(7414), 557-560.

Ho, C. P. (2008). Effect of Work/Rest Patterns and Lumbar Support Belt on Data-Entry Task. Journal of the Chinese Institute of Industrial Engineers, 25(1), 43-51.

Hockey, G. R. J. (1997). Compensatory control in the regulation of human performance under stress and high workload: A cognitive-energetical framework. Biological Psychology, 45, 73-93.

Hockey, G. R. J. (2011). A motivational control theory of cognitive fatigue. In: P. L. Ackerman (Ed.), Cognitive fatigue: Multidisciplinary perspectives on current research and future applications. (pp. 167-187). Washington, DC: American Psychological Association.

${ }^{*}$ Hüttges, A., Müller, A. and Richter, P. (2005). Gesundheitsförderliche Arbeitsgestaltung durch Kurzpausensysteme: Ein Ansatz an der Schnittstelle von Verhaltens- und Verhältnisprävention. [Workplace health promotion with short rest breaks: An approach at the interface of behavior prevention and relational prevention]. Wirtschaftspsychologie, 7(3), 36-43.

Karwowski, W., Eberts, R., Salvendy, G. and Noland, S. (1994). The effects of computer interface design on human postural dynamics. Ergonomics, 37(4), 703-724.

Kennedy, C., Amick Iii, B., Dennerlein, J., Brewer, S., Catli, S., Williams, R., . . Rempel, D. (2010). Systematic Review of the Role of Occupational Health and Safety Interventions in the Prevention of Upper Extremity Musculoskeletal Symptoms, Signs, Disorders, Injuries, Claims and Lost Time. Journal of Occupational Rehabilitation, 20(2), 127-162.

Kraepelin, E. (1902). Die Arbeitscurve [The curve of work]. Philosophische Studien, 19, 459-507.

Konz, S. (1998). Work/rest: Part II - The scientific basis (knowledge base) for the guide. International Journal of Industrial Ergonomics, 22, 73-99.

Lehmann, G. (1958). Physiological measurements as a basis of work organization in industry. Ergonomics, 1(4), 328-344.

Lehmann, G. (1962). Praktische Arbeitsphysiologie [Work physiology in practice]. Stuttgart: Thieme.

LePine, J. A., Podsakoff, N. P. and LePine, M. A. (2005). A meta-analytic test of the challenge stressorhindrance stressor framework: An explanation for inconsistent relationships among stressors and performance. Academy of Management Journal, 48, 764-775.

Linder, M. and Nygaard, I. (1998). Void where prohibited: Rest breaks and the right to urinate on company time. Ithaca, New York: ILR Press.

Lipsey, M. W. and Wilson, D. B. (2001). Practical meta-analysis. Thousand Oaks, CA: Sage Publications.

Lohmann-Haislah, A. (2012). Stressreport Deutschland 2012. Psychische Anforderungen, Ressourcen und Befinden [Stress report 2012: Mental demands, resources, and well-being]. Dortmund: Bundesanstalt für Arbeitsschutz und Arbeitsmedizin.

Manzer, C. W. (1927). An experimental investigation of rest pauses. Archives of Psychology, 90, 1-84. 
McCann, D. (2005). Working time laws: A global perspective. Geneva: International Labour Organization.

McGehee, W. and Owen, E. B. (1940). Authorized and unauthorized rest pauses in clerical work. Journal of Applied Psychology, 24(5), 605-614.

McLean, L., Tingley, M., Scott, R. N. and Rickards, J. (2001). Computer terminal work and the benefit of microbreaks. Applied Ergonomics, 32(3), 225-237.

Meijman, T. F. and Mulder, G. (1998). Psychological aspects of workload. In: P. J. D. Drenth and H. Thierry (Eds.), Handbook of work and organizational psychology, Vol. 2: Work psychology (pp. 5-33). Hove, UK: Psychology Press.

Müller-Seitz, P. (1996). Erfolgsfaktor Arbeitszeit: Optimale Arbeitszeitsysteme aus betriebswirtschaftlicharbeitswissenschaftlicher Sicht [Successful working time schedules: Optimal working time systems from an economic and ergonomic point of view]. München: Beck.

Moher, D., Liberati, A., Tetzlaff, J. and Altman, G.D. (2009). The PrIsMA group preferred reporting items for systematic reviews and meta-analyses: The PrIsMA statement. Open Medicine, 3(2), 123130.

Nachreiner, F., Wirtz, A., Dittmar, O, Chomann, C. and Bockelmann, M. (2010). Study to support an impact assessment on further action at European level regarding directive 2003/88/EC and the evolution of working time organisation: Annex 1 - Study on health and safety aspects of working time. Retrieved on 04.05 .2016 from http://ec.europa.eu/social/main.jsp?catId=157\&langId= de\&moreDocuments $=$ yes\&newsId $=964 \&$ tableName $=$ news.

Nahrgang, J. D., Morgeson, F. P. and Hofmann, D. A. (2011). Safety at work: A meta-analytic investigation of the link between job demands, job resources, burnout, engagement, and safety outcomes. Journal of Applied Psychology, 96, 71-94.

Ng, T. W. H. and Feldman, D. C. (2008). Long work hours: A social identity perspective on metaanalysis data. Journal of Organizational Behavior, 29(7), 853-880.

Nixon, A. E., Mazzola, J. J., Bauer, J., Krueger, J. R. and Spector, P. E. (2011). Can work make you sick?: A meta-analysis of job stressor-physical symptom relationships. Work \& Stress, 25(1), 1-22.

O’Donnell, E., Landolt, K., Hazi, A., Dragano, N. and Wright, B. J. (2015) An experimental study of the job demand-control model with measures of heart rate variability and salivary alpha-amylase: Evidence of increased stress responses to increased break autonomy. Psychoneuroendocrinology, 51, 24-34.

${ }^{\star}$ Paulus, P. B., Nakui, T., Putman, V. L. and Brown, V. R. (2006). Effects of task instructions and brief breaks on brainstorming. Group Dynamics: Theory, Research, and Practice, 10(3), 206-219.

Podsakoff, N. P., LePine, J. A. and LePine, M. A. (2007). Differential challenge stressor- hindrance stressor relationships with job attitudes, turnover intentions, turnover, and withdrawal behavior: A meta-analysis. Journal of Applied Psychology, 92(2), 438-454.

Praetsch, B. (2013). Der Einfluss von Freiheitsgraden in der Kurzpausenorganisation bei verschiedenen Anforderungshöhen der Arbeit auf die Entwicklung von Fehlbeanspruchungsfolgen [The impact of rest break control on strain a different levels of mental demands]. Dresden: TU Dresden.

Richter, P. and Hacker, W. (2014). Belastung und Beanspruchung: Stress, Ermüdung und Burnout im Arbeitsleben (4. Aufl.) [Stress and strain: Stress, Fatigue, and Burnout]. Kröning: Asanger. 
Rivers, W. H. R. and Kraepelin, E. (1896). Über Ermüdung und Erholung [Fatigue and recovery]. Psychologische Studien, 1(4), 627-678.

Rohmert, W. (1973a). Problems in determining rest allowances. Part 1: use of modern methods to evaluate stress and strain in static muscular work. Applied Ergonomics, 4(2), 91-95.

Rohmert, W. (1973b). Problems in determining rest allowances. Part 2: determining rest allowances in different human tasks. Applied Ergonomics, 4(3), 158-162.

Ross, S. and Bricker, P. D. (1951). The effect of an amount set on a repetitive motor task. Journal of Experimental Psychology, 42(1), 39-43.

Rutenfranz, J. and Iskander, A. (1966). Über den Einfluss von Pausen auf das Erlernen einer einfachen sensumotorischen Fertigkeit [On the effect of intervals on the acquisition of simple sensorimotor skills]. Internationale Zeitschrift für angewandte Physiologie einschließlich Arbeitsphysiologie, 22(3), 207-235.

Rutenfranz, J. and Stoll, F. (1966). Untersuchungen über die Verteilung von Pausen bei freier Arbeit [Studies on the distribution of breaks at self-paced work]. Arbeitswissenschaft, 5, 132-135.

Sarna, L., Aguinaga Bialous, S., Wells, M. J., Kotlerman, J., Froelicher, E. S. and Wewers, M. E. (2009). Do you need to smoke to get a break?: Smoking status and missed work breaks among staff nurses. American Journal of Preventive Medicine, 37(2 Suppl), 165-171.

Schmatz, V. and Klingebiel, A. (2012). Der Einfluss von Freiheitsgraden bei der Kurzpausenorganisation auf die Entwicklung von Fehlbeanspruchungsfolgen [The impact of rest break control on mental strain]. Dresden: TU Dresden.

Schmidtke, H. (1993). Ergonomie. München: Hanser.

Scholz, O. B. (1970). Zur Diagnostik des Ermüdungs-, Monotonie- und Sättigungserlebnisses - Vorläufige Mitteilung über die Konstruktion eines Fragebogens [Assessment of fatigue, monotony and mental satiation - Preliminary note on the construction of a questionnaire]. Zeitschrift für Psychologie, 178(3/4), 203-225.

Sio, U. N. and Ormerod, T. C. (2009). Does incubation enhance problem solving? A meta-analytic review. Psychological Bulletin, 135(1), 94-120.

Sonnentag, S., Volmer, J. and Spychala, A. (2008). Job performance. In: J. Barling and C. L. Cooper (Eds.), The Sage handbook of Organizational Behavior. Volume 1: Micro approaches (pp. 427-447). Los Angeles: Sage.

Sonnentag, S. and Frese, M. (2012). Stress in organizations. In: I. B. Weiner, N. W. Schmitt and S. Highhouse (Eds..), Industrial and organizational Psychology. (2. ed.:560-592). (Comprehensive Handbook of Psychology; Band 12). New York: John Wiley \& Sons.

Sparks, K., Cooper, C., Fried, Y. and Shirom, A. (1997). The effects of hours of work on health: A meta-analytic review. Journal of Occupational and Organizational Psychology, 70(4), 391-408.

Sturman, M. C., Cheramie, R. A. and Cashen, L. H. (2005).The impact of job complexity and performance measurement on the temporal consistency, stability, and test-retest reliability of employee job performance ratings [Electronic version]. Retrieved [01.05.2016], from Cornell University, School of Hospitality Administration site: http://scholarship.sha.cornell.edu/articles/120.

Szalma, J. A., Hancock, P. A. and Quinn (2008). A meta-analysis of the effect of time pressure on human performance. Proceedings of the Human Factors and Ergonomics Society, 52(19), 1513-1516. 
Trougakos, J. P. and Hideg, I. (2009). Momentary work recovery: The role of within-day work breaks. In: S. Sonnentag, P. L. Perrewé \& D. C. Ganster (Eds.), Current Perspectives on Job-Stress Recovery. Research in Occupational Stress and Well-being (7, 37-84). Bingley: Emerald Group Publishing Limited.

Tucker, P. (2003). The impact of rest breaks upon accident risk, fatigue and performance: A review. Work \& Stress, 17(2), 123-137.

${ }^{*}$ van den Heuvel, S. G., de Looze, M. P., Hildebrandt, V. H. and The, K. H. (2003). Effects of software programs stimulating regular breaks and exercises on work-related neck and upper-limb disorders. Scandinavian Journal of Work, Environment and Health, 29(2), 106-116.

van Holland, B. J., Soer, R., Boer, M. R., Reneman, M. F. and Brouwer, S. (2015). Preventive occupational health interventions in the meat processing industry in upper-middle and high-income countries: a systematic review on their effectiveness. International Archives of Occupational and Environmental Health, 88(4), 1-14.

Vernon, H. N. (1925). Can laboratory experiments on output throw light on problems of industrial fatigue? British Journal of Psychology - General Section, 15(4), 393-404.

Wegge, J., Wendsche, J. and Diestel, S. (2014). Arbeitsgestaltung [Job design]. In: H. Schuler and K. Moser (Eds.), Lehrbuch Organisationspsychologie (pp. 315-367). Göttingen: Hogrefe.

Wendsche, J., Hacker, W., Wegge, J., Schrod, N. Roitzsch, K., Tomaschek, A. and Kliegel, M. (2014). Rest break organization in geriatric care and turnover: A multimethod cross-sectional study. International Journal of Nursing Studies, 51(9), 1246-1257.

Wendsche, J. and Wegge, J. (2014). Ein Rahmenmodell zur Anwendung von Kurzpausensystemen im Arbeitskontext [A framework to apply rest break schedules]. In: M. Eigenstetter, T. Kunz, R. Portune and Trimpop, R. (Eds.), Psychologie der Arbeitssicherheit und Gesundheit - Psychologie der gesunden Arbeit - 18. Workshop 2014 (pp. 439-442). Kröning: Asanger.

Zacher, H., Brailsford, H. A. and Parker, S. L. (2014). Micro-breaks matter: A diary study on the effects of energy management strategies on occupational well-being. Journal of Vocational Behavior, 85(3), 287-297.

Zijlstra, F. R. H., Cropley, M. and Rydstedt, L. W. (2014). From recovery to regulation: An attempt to reconceptualize 'recovery from work'. Stress and Health, 30(3), 244-252. 